\title{
O perfil de jornalistas na cobertura especializada em ciência
}

\author{
Profile of Brazilian journalists in covering science
}

\author{
Marli dos Santos ${ }^{1}$ \\ (marli.santos@metodista.br) \\ http://dx.doi.org/10.5216/cei.v15i1.22510
}

\begin{abstract}
Resumo
Este artigo trata do perfil de jornalistas brasileiros na cobertura especializada em ciência em São Paulo. O objetivo é investigar algumas pistas sobre a influência do perfil do jornalista na produção da informação científica, além de reflexões acerca da qualidade na cobertura. Para isso, foi realizado um levantamento das características dos profissionais que atuam em jornalismo científico na cidade de São Paulo, em revistas, jornais e internet, bem como suas opiniões a respeito do perfil e da cobertura em ciência, por meio de questionários com perguntas fechadas e abertas. Trata-se de amostra não-probabilística, por acessibilidade. O principal resultado aponta para a formação especializada como principal motivo de mudança no perfil dos profissionais, porém isso ainda não reflete na qualidade da cobertura jornalística em ciência.
\end{abstract}

Palavras-chave: Jornalismo Especializado. Jornalismo Científico. Perfil de Repórteres. Folha de São Paulo. O Estado de S. Paulo. Superinteressante. Galileu.

\begin{abstract}
This article deals with the profile of Brazilian journalists in covering science specializing in São Paulo. The objective is to investigate some clues about the influence of profile journalist in the production of scientific information, as well as reflections on the quality of coverage. For this, a survey was conducted of the characteristics of professionals working in science journalism in the city of São Paulo, in magazines, newspapers and internet, as well as their opinions about the profile and coverage in science, through questionnaires with closed questions and open. It is non-probabilistic sample, for accessibility. The main result points to the specialized training as the main reason for change in the profile of the professionals, but that still does not reflect the quality of science coverage.
\end{abstract}

Keywords: Specialized Journalism. Scientific Journalism. Profile Reporters. Folha de S. Paulo. O Estado de S. Paulo. Superinteressante. Galileu.

\section{Introdução}

Jornalista é um especialista em generalidades! Diante dessa pseudo-definição que se repete nas escolas quando se tenta falar desse profissional, surgem crises de identidade, discussões sobre o

1 Universidade Metodista de São Paulo, São Paulo, Brasil.

Comun. \& Inf., v. 15, n.1, p. 197-216, jan./jun. 2012 
currículo ideal para a formação do jornalista, e até preconceito. O profissional do jornalismo atua na cobertura de diversos assuntos, em diversos níveis de profundidade, em várias plataformas e suportes, em diferentes linguagens, em diferentes funções, dentro e fora das redações, com vínculo empregatício ou não. Mas isso não é novidade, não é coisa de agora, sequer do século 20.

Desde seu surgimento a imprensa mostrou e mostra a sua versatilidade. No quesito assunto, vem ampliando o leque de temas ou se especializando em alguns, de acordo com a demanda da sociedade, marcada pelo contexto histórico. É só observar as diferentes editorias nos jornais impressos; os milhares de títulos de revistas; o jornalismo de rádio e $\mathrm{TV}$, com seus boletins e programas especializados; a internet, com blogs, sites jornalísticos. Por isso, há muito que se estudar sobre jornalismo especializado e os profissionais que nele atuam.

Este artigo pretende apresentar o perfil de jornalistas que atuam na grande imprensa e na mídia especializada em ciência na cidade de São Paulo. São repórteres e editores ligados a jornais, revistas e internet, meios que normalmente possuem editorias ou veículos especializados na área. Trata-se de estudo de campo, cujo instrumento de pesquisa foi um questionário com perguntas abertas (2) e fechadas (11 questões), enviado por email. Foram 116 profissionais contatados, nomes obtidos em listagem elaborada e disponibilizada por empresa especializada em cadastros de jornalistas, organizada por nome, veículo e email. Destes, 20 responderam em tempo hábil. Trata-se de uma amostra não-probabilística por acessibilidade.

Alguns autores referidos neste texto, como Groth, Rovida, Tavares, Bueno, Caldas, entre outros, contribuem para pensar o jornalismo especializado, diferenciando-o do segmentado; o jornalismo científico; e o perfil de jornalistas que atuam na área de ciência na cidade de São Paulo.

\section{Jornalismo especializado e/ou segmentado?}

No Brasil, alguns pesquisadores - pouquíssimos, a bem da verdade -, se dedicaram a buscar conceitos, semelhanças e diferenças entre jornalismo, jornalismo especializado e jornalismo segmentado - se é que podemos pensar em conceitos diferentes para o jornalismo especializado e segmentado. Dines já dizia em artigo publicado na revista Aberje - Associação Brasileira de Comunicação Empresarial (1996) que não há “jornalismos”, o jornalismo é um só.

Um dos primeiros autores a fazer um estudo para entender o jornalismo, ou "a ciência dos jornais" - expondo diferenças e semelhanças entre jornais e revistas -, foi Otto Groth (2011). O autor se dedicou ao estudo do jornalismo, observando inúmeras publicações para buscar um padrão 
que o identificasse, atitude própria dos cientistas para entender os fenômenos. Groth chegou aos conceitos fundantes desse fenômeno cultural, que à época já apresentava diversas manifestações, em suportes diferentes, com diversas temáticas, periodicidade e difusão distintas. Universalidade, periodicidade, difusão e atualidade são as características definidoras do jornalismo, segundo o autor.

Tendo em vista que jornalismo, independentemente de seu tema, suporte ou linguagem, deve ter essas características estruturantes, resta-nos pensar o que caracteriza o jornalismo especializado.

Fontcuberta, citado por Tavares (2011), define o tema como a "razão de ser" do jornalismo especializado, o que implica em produção, linguagem e recepção diferenciados.

Rovida (2010) concorda que a especialização do jornalismo está ligada ao tema, ou seja, a um jornalismo temático, mas não perde o seu caráter abrangente. Não é dirigido apenas a um segmento específico, ao contrário do jornalismo segmentado. Essa última modalidade atende às demandas de uma parcela da população, de alguns grupos, superespecializando a comunicação (ROVIDA, 2010). Superespecializar é diminuir sensivelmente as possibilidades de uma comunicação mais ampla:

O jornalismo especializado, normalmente, se remete a uma editoria do jornalismo de informação geral, não sendo considerado um fenômeno ou modalidade a parte [...]. Especialização maior acaba por restringir a comunicação jornalística a interesses de um grupo de pessoas específico e aquela noção de comunicação generalista voltada a um público amplo perde espaço para uma comunicação focada em um público específico, com interesses e necessidades bem definido ROVIDA, 2010, p. 65-66).

A autora ainda esclarece que a segmentação de público é muito mais presente nas revistas, nas quais abordagens e linguagens são adequadas a determinados segmentos.

Nesse tipo de periódico observamos com muito mais clareza a diferença entre o jornalismo especializado e essa outra modalidade de jornalismo que é superespecializado e acaba limitando, ou seja, segmentando seu público (ROVIDA, 2010, p. 65-66).

Comun. \& Inf., v. 15, n.1, p. 197-216, jan./jun. 2012 
Apesar de Rovida considerar o jornalismo especializado e dirigido a um segmento como uma superespecialização do jornalismo, Navarro (2010), em seu estudo sobre o jornal Meio\&Mensagem, analisa os momentos de convergência entre especialização e segmentação:

Sob tal ótica, pode-se concluir que jornalismo especializado e jornalismo segmentado podem convergir em dois casos: A) quando um veículo segmentado publica periodicamente reportagens sobre determinado assunto, com aprofundamento em suas especificidades (um jornal sobre marketing que veicula matérias sobre marketing esportivo no Brasil, por exemplo); e B) quando determinada editoria ou seção de uma publicação, por efeito de tradição e/ou retorno superlativo dos consumidores de informação, torna-se uma parte noticiosa com um conjunto de regras próprias de seu ato de informar, inclusive com atração publicitária diferente ou mais específica em relação às demais partes do veículo (uma coluna sobre música pop num jornal genérico de grande tiragem, por exemplo). (NAVARRO, 2010, p. 12).

É certo que o jornalismo especializado em veículos segmentados muitas vezes possui características diferenciadas em relação às editorias nos jornais de grande circulação, como por exemplo, a linguagem adequada ao grupo ao qual se dirige. Exemplos disso são as revistas Superinteressante (Editora Abril) e Galileu (Editora Globo). Porém, não podemos deixar de considerá-lo como jornalismo especializado, tendo em vista a temática.

Tavares (2007) também menciona as revistas como espaço tradicional do jornalismo especializado, reconhecendo que essas publicações, desde seu surgimento, têm se dedicado a assuntos da contemporaneidade, encontrando nela (a vida presente) a oportunidade para lançar novos e diferentes títulos. $\mathrm{O}$ autor cita Giddens para analisar as brechas que a vida contemporânea propicia, criando "novas demandas para o surgimento e/ou destaque de uma participação especializada na sociedade, ou melhor, para a evidência e importância de certos saberes especializados e de certos especialistas" (2007, p. 23).

[...] ciência, tecnologia e especialização desempenham um papel fundamental naquilo que ele aponta ser uma segregação da experiência, processo iniciado na modernidade e cuja lógica implica na ocultação pelos sistemas abstratos de certos fenômenos/problemas que atrapalhariam as regularidades e seguranças da vida cotidiana. Nesse contexto, se pensarmos o papel da mídia, é inevitável que alcancemos a participação da chamada cultura de massa e seus produtos (TAVARES, 2007, p. 24, grifo do autor). 
Embora a especialização no jornalismo tenha se manifestado desde os primórdios, é com o advento dos meios eletrônicos de massa, como o rádio e a televisão, e a sua consolidação nos anos 1960 e início de 70, que "entra em cena a especialização propriamente dita". "Historicamente, a especialização periodística está associada, em sua maioria, à evolução dos meios de comunicação e a formação de grupos sociais consumidores de mídia cada vez mais distintos” (TAVARES, 2009, p. 117).

Em outras palavras, quanto mais avançam o capitalismo e as tecnologias, maior a tendência à segmentação e à especialização. Novos grupos de consumidores se formam, muitas vezes em escala planetária, e as novas tecnologias tratam de transformar em realidade novas demandas desses grupos. Como menciona Genro (1987), o jornalismo é filho de "um consórcio histórico entre o capitalismo e as tecnologias". Tavares ressalta a importância dos processos tecnológicos e sociais na fragmentação de conteúdos:

Neste cenário temos como protagonista a imprensa e as conseqüências deste processo tecnológico e social sobre ela.

Do ponto de vista dos conteúdos, dada a sua vocação de falar do mundo como um "todo", buscando dar conta desse "todo", a imprensa, como primeiro grande meio de comunicação jornalístico, sempre esteve fragmentada, falando "genericamente de coisas específicas". Sua especialidade, pela palavra autorizada e pela fragmentação dos conteúdos, sempre existiu. No entanto, com a introdução de outros meios e, consequentemente de outros regimes de produção (de noticiabilidade, visibilidade e periodicidade), tal especialidade passou a bater de frente com a lógica da especialização, ou seja, de uma outra especialidade jornalística (TAVARES, 2009, p.117-118).

Ainda de acordo com Tavares (2009), que cita Fontcuberta, a especialização jornalística deve ser pensada como uma maneira diferente de se fazer jornalismo. Não se trata apenas de conteúdo e público específicos, mas de considerar um cenário em que tecnologias, capitalismo e diversos suportes midiáticos constituem um amálgama para uma produção jornalística diferenciada, especialmente no que diz respeito ao que é noticiado e à linguagem.

Atribui-se a esse tipo de jornalismo, portanto, o papel de buscar intermediar saberes especializados na sociedade, construindo um tipo de discurso que, noticioso, ou "apenas" informacional, promova um outro tipo de conhecimento que se funde - geralmente - na compreensão conjunta do universo científico e do senso comum. Uma característica que, como aponta o professor Esteve Ramírez (1999) marca o seu "lugar" como disciplina, direcionando e formatando seus objetos de estudo, assim como construindo seu próprio paradoxo epistemológico: o 
Jornalismo Especializado é "una disciplina especializada en unificar las distintas especializaciones” (TAVARES, 2009, p. 123).

Um exemplo desse saber especializado é analisado por Moraes (2011) sobre a Superinteressante, considerada revista especializada em jornalismo científico. O estudo realizado pela pesquisadora constatou-se que a revista tem uma maneira peculiar de relatar a realidade em suas reportagens. Algumas das regras básicas do jornalismo, como a citação da fonte para reforço da informação, são quase menosprezadas em alguns momentos, pois o jornalista é o maior "fiador" da informação levada ao público. Nas matérias publicadas na revista e estudadas por Moraes quase não há dados sobre a metodologia de pesquisa; enfatizam-se os resultados e aplicação prática dos estudos, passando uma visão pragmática da ciência; o pesquisador é citado "como alguém que ratifica ou reforça a ideia exposta pelo jornalista" (MORAES, 2011). Jornalistas especialistas ou especialistas jornalistas?

Nas redações convivem os dois, jornalistas especializados e especialistas jornalistas. E ainda os diplomados e os que se formaram na prática da redação. Somam-se os que possuem outra formação, mas atuam como jornalistas. E isso tudo pode existir em uma só redação.

O fato estudos realizados em alguns países mostram que os jornalistas por formação ainda são a maioria nas redações (2011). Tavares (2009) fez uma revisão bibliográfica sobre o assunto e ressalta a contribuição de pesquisadores brasileiros sobre o jornalista especializado. De acordo com Lage, citado por Tavares, questões éticas, técnicas e econômicas levam à conclusão que é muito melhor para os veículos o jornalista se especializar que o especialista se transformar em um jornalista.

Especializar-se seria então ter um conhecimento aprofundado sobre o assunto, seja política, economia ou ciência. É preciso conhecimento técnico, investigação, o que Tavares denomina como metodologia de trabalho, que inclui, em síntese, investigação, interpretação e precisão (TAVARES, 2009). Porém, investigar, interpretar e ser preciso nos fatos não é privilégio do jornalismo especializado, é princípio do jornalismo.

Apesar de o procedimento apontado por Tavares serem os mesmos para quem faz jornalismo, especialmente para quem faz reportagem, Scalzo, citada por Tavares (2009), também destaca que o jornalista especializado aprofunda conhecimento sobre uma temática, e isso é um fator diferenciador entre generalistas e especialistas. Além disso, o texto também é uma característica apontada como diferencial do jornalista especializado, uma vez que ao imergir sempre 
em uma mesma temática o texto será resultado dessa experiência, terá mais profundidade. Dentre os gêneros jornalísticos, a reportagem é apontada como gênero que representa o jornalismo especializado, em razão dos métodos de apuração (TAVARES, 2011).

Embora o jornalismo especializado tenha as características acima apontadas, ao observar os conteúdos em veículos especializados e editorias, verificamos que há uma profusão de gêneros jornalísticos: a reportagem, a notícia, o artigo, as espécies práticas, de acordo com a classificação de Chaparro (1998). Assim, em uma revista que se autodenomina especializada em ciência, ou editoria, a primazia de alguns gêneros e a profundidade com que são abordadas as pautas sobre uma temática representam muito mais estratégias editoriais de acordo com os públicos atingidos.

Portanto, a qualidade de um produto jornalístico especializado depende de muitas variáveis. O uso de metodologias de trabalho para apuração dos fatos, bem como o resultado em texto, vídeo e áudio desse processo estão vinculados ao perfil editorial do veículo, ao público-alvo e à competência da equipe de profissionais.

\section{Jornalismo científico, jornalistas e veículos}

De acordo com Bueno, "O Jornalismo Científico, que deve ser em primeiro lugar Jornalismo, depende estritamente de alguns parâmetros que tipificam o jornalismo, como a periodicidade, a atualidade e a difusão coletiva" (BUENO, 2011). Assim, não dá para dizer que há um jornalismo científico diferente de outro jornalismo no que se refere a seus conceitos fundantes.

Mas há um aspecto importante que Bueno destaca: jornalismo científico é diferente de divulgação científica ou de disseminação científica. Este último é uma divulgação da pesquisa científica entre pares (cientistas ou iniciados), como os artigos científicos que possuem um tratamento e uma linguagem de acordo com o campo do saber. Já a divulgação científica tem em comum com o jornalismo científico o fato de abranger públicos leigos, porém com uma diferença fundamental: a primeira utiliza diversas formas para divulgar a ciência, como fascículos, livros didáticos, peças de teatro, músicas, entre outros, ou seja, diversas linguagens. O jornalismo científico não. Assim, “O Jornalismo Científico diz respeito à divulgação da ciência e tecnologia pelos meios de comunicação de massa, segundo os critérios e o sistema de produção jornalística" (BUENO: 2011). 
O JC abrange as ciências físicas, biológicas, exatas, humanas e sociais (embora as pautas acabem priorizando as ciências físicas e biológicas). E, segundo Bueno, em razão das especializações, tem assumido

[...] denominações particulares, em alguns casos, como o Jornalismo Ambiental, o Jornalismo em Agribusiness, o Jornalismo em Saúde, o Jornalismo Econômico, o Jornalismo em Informática etc. Na prática, no entanto, todas estas manifestações específicas remetem para o Jornalismo Científico, entendido aqui como o termo genérico, mais abrangente (BUENO, 2011, p.).

No entanto, nem sempre as especialidades indicadas podem ser consideradas sob um mesmo guarda-chuva. Isso porque teríamos então de incluir o jornalismo político, entre outros, nesse mesmo patamar. O fato é que esses limites são bem complicados de se estabelecer, o que não é objetivo deste artigo.

Outros aspectos são analisados por Bueno em relação ao jornalismo científico. Embora haja crescimento no número de títulos de publicações, de espaços, de profissionais competentes, de oferta de cursos para formação especializada, essas conquistas ainda não consolidam um espaço efetivo para o jornalismo científico. Exemplos são as TVs e rádios "que continuam abdicando do seu compromisso de formar e informar adequadamente a opinião pública", por interesses particulares e comerciais dos veículos.

Na visão de Bueno,

O jornalismo científico no Brasil, com as exceções de praxe (e não são muitas) continua pouco investigativo, refém das pautas externas e de temas muitas vezes deslocados da nossa realidade. Certamente, a falta de uma "cultura de comunicação" nas nossas principais universidades, empresas e institutos de pesquisa; e a falta de consciência dos editores e empresários da comunicação, que buscam pautas óbvias, oficialescas, contribuem para isso (BUENO, 2011).

A crítica que o autor faz pode ser aplicada às outras áreas do jornalismo, porém, é importante ressaltar que em cada área há especificidades.

Assim, uma das frentes para melhorar a cobertura no jornalismo científico é a formação do profissional. Caldas citada por Carvalho (2011) afirma ser necessário que o jornalista científico esteja preparado para não só saber lidar com as fontes, como os cientistas - muitas vezes avessos

Comun. \& Inf., v. 15, n.1, p. 197-216, jan./jun. 2012 
aos jornalistas, como também entender sobre história e filosofia da ciência, ética na ciência, linguagem científica, metodologia da ciência, entre outros conhecimentos.

Em estudo sobre a formação em jornalismo científico tanto na graduação quanto na pósgraduação, realizado por Caldas et al (2011), verificou-se que a maioria dos cursos de jornalismo existentes no Brasil não incorporou disciplinas sobre o tema, apesar da crescente importância da ciência na vida do cidadão e da responsabilidade social do jornalismo. A autora tem razão em ressaltar essa defasagem já na graduação, pois os alguns cursos oferecem disciplinas como jornalismo econômico, político, cultural, mas não científico.

Já na pós-graduação, embora haja disciplinas específicas, há alguns problemas nos enfoques e abordagens, que geram também reflexos na cobertura mais ligeira, com ênfase no resultado da pesquisa e não no processo.

O pragmatismo formador dos conteúdos limita o papel dos jornalistas a uma perspectiva reducionista e meramente funcionalista. Quanto mais positivista a formação - pragmática, objetivista, resultado em detrimento do processo - mais positivista tende a ser a produção (CALDAS et al, 2011, p. 13).

\section{Pistas para um perfil}

Como definiu Groth (2011),

[...] jornalistas especialistas são primeiro os jornalistas que se voltam a uma "disciplina" que é especializada profissionalmente e cujo exercício exige instrução e treinamento técnico. ...Há sempre muita coisa específica que é interessante e significativa para além do círculo da disciplina, para a coletividade, que tem influência direta sobre o desenvolvimento (GROTH, 2011, p. 359).

Tendo em vista a importância da ciência, do jornalismo especializado e dos profissionais que atuam na área para informar e formar a sociedade sobre temas que são fundamentais no seu cotidiano, foi realizada um levantamento sobre o perfil do jornalista especializado em ciência, bem como o que ele pensa sobre a cobertura na área.

O primeiro passo foi definir a população da pesquisa por meio de um cadastro profissional e atualizado sobre jornalistas que atuam em ciência. Depois de verificado que São Paulo é a cidade que mais possui profissionais que atuam nessa área, além de também sediar alguns dos principais veículos de comunicação jornalística, o segundo filtro foi o tipo de veículo de comunicação.

Comun. \& Inf., v. 15, n.1, p. 197-216, jan./jun. 2012 
Uma vez verificado que a quantidade de profissionais estava concentrada em jornais, revistas e internet (a TV e o rádio não entraram nessa amostra, embora se entenda a importância desses veículos para a disseminação de uma cultura científica à população), o terceiro critério foi a função exercida na redação. Nesse quesito foram selecionados editores-chefe, subeditores, editores assistentes e repórteres.

Os questionários foram enviados no final do mês de fevereiro, com apenas um reenvio. Desses 15 voltaram por "falhas na distribuição", as quais remetiam à caixa de emails lotada e ao destinatário não localizado. No primeiro retorno foram respondidos 15 questionários. No segundo, mais cinco, sendo que 4 jornalistas se manifestaram dizendo que não faziam parte do perfil desejado, por não atuarem mais em ciência. No total, por ser uma amostragem não probabilística por acessibilidade, obteve-se 20 questionários, porém, nem todas as questões foram respondidas por todos, havendo uma variação de respostas não emitidas. É importante ressaltar que também em relação à função exercida houve discrepância quanto à participação, conforme mostra quadro acima.

Assim, mesmo com todas as dificuldades em contar com a participação dos jornalistas nessa área, foi possível observar algumas tendências e percepções desses profissionais na amostra considerada para este artigo.

Dos respondentes, a maioria (9) está na faixa entre 30 e 40 anos, sendo 4 respondentes de 26 a 30 e 4 com mais de 40 anos. Em razão de 13 exercerem a função de editor, é compreensível que a faixa etária mais presente esteja entre 30 e 40 anos, pressupondo que o exercício da função requer experiência. Três dos respondentes são repórteres, dois com vínculo empregatício e outro freelancer. Um exerce a função de estagiário, e 3 não responderam a função.

Houve um equilíbrio no retorno de jornalistas que atuam em revistas e internet ( 7 cada tipo de veículo). Apenas 3 são de editorias de ciência de jornais impressos e os demais não responderam. A maioria dos que responderam as questões atua em veículos de grande circulação, como os jornais impressos O Estado de S. Paulo, Folha de S.Paulo, Jornal da USP; revistas Unesp Ciência, Newslab, Pesquisa Fapesp, National Geographic Brasil, Superinteressante; internet: Portal do jornalismo Científico Online, Info Oline, site da National Geographic, Veja online, Pesquisa Fapesp. Um dos respondentes atua em versão áudio de um mesmo veículo.

A maioria dos que atuam em jornalismo especializado em ciência é formada em jornalismo. Quinze dos respondentes são jornalistas graduados, sendo que apenas 4 têm formação (completa ou incompleta) em outras áreas, como ciências físicas e biológicas, ciências exatas e engenharia.

Comun. \& Inf., v. 15, n.1, p. 197-216, jan./jun. 2012 
Dos que responderam a pesquisa, 10 possuem outros cursos, como o de especialização em jornalismo científico em instituições como Knight Science Journalism Felowships at MIT, Labjor Laboratório de Jornalismo - da Unicamp, Campina/SP, Núcleo José Reis da ECA-USP, Faculdade Cásper Líbero, em São Paulo; Jornalismo em Ciência e Saúde no Instituto das Américas, Califórnia - EUA; Jornalismo, Educação e Ciência pela PUC-SP; Programa de Estudos no Reuters Institute for the Study in Journalism, Universidade de Oxford, Inglaterra; e ainda graduações em Matemática e Biologia e mestrado em neurociência. Três dos respondentes possuem mestrado ou doutorado na área de jornalismo científico.

Quanto à experiência anterior na área de ciência, 13 dos respondentes disseram ter experiência anterior a atual, como em outros veículos de comunicação, em assessoria de imprensa, em grandes empresas, em estudos acadêmicos como iniciação científica, mestrado e doutorado e estágio de graduação em outra área da ciência.

Tanto no que se refere à formação quanto à experiência anterior, se observa uma tendência à especialização, uma vez que na sua maioria os profissionais que responderam a pesquisa possuem entre 30 e 40 anos e estão em cargos de chefia. Porém, não é possível fazer nenhuma afirmação quanto a diferenças entre formação de repórteres e editores já que houve uma discrepância no número de questionários respondidos pelos participantes em funções diferentes.

Já quando questionados sobre a necessidade ou não de formação específica na área, a amostra se dividiu: 9 disseram que sim e 10 responderam não. Cruzando esse total com os que fizeram algum curso de especialização (10), é possível dizer, numa análise mais apressada, que naturalmente os que fizeram cursos indicam a necessidade da realização dos mesmos. Porém, ao observar mais detalhadamente os que responderam não a essa questão, observamos que 4 possuem formação específica. Dos que disseram sim, dois não possuem especialização na área. Esse dado sugere maior investigação para entender por que os jornalistas que se especializam ainda sim consideram esse preparo desnecessário ao profissional da área.

De certa forma, o resultado da questão seguinte confirma a constituição da amostra, formada na maioria por jornalistas editores. Na questão 10 a pergunta foi quanto à experiência profissional na área de ciência. Oito participantes têm mais de 10 anos na cobertura especializada, somados aos 3 que disseram ter entre 5 e 10 anos, temos um total de 11 jornalistas com boa e ótima experiência na área. Seis dos respondentes disseram ter entre 2 e 5 anos de experiência. 
A penúltima questão exigia a escolha de uma alternativa e a devida justificativa. A pergunta era "Como avalia a cobertura de ciência nos principais veículos jornalísticos brasileiros dirigidos ao público leigo?", com as alternativas: ótima, boa, regular e ruim. Dez respondentes disseram que a cobertura é regular, sendo que 6 apontaram como boa e um ruim.

As justificativas mais relevantes para as respostas que variam de regular a boa, valorizam parte da produção jornalística especializada na área, porém, ainda consideram necessário aprimorar:

Leio o "estadão" diariamente e a cobertura dessa área "eh" muito boa, "tb" leio algumas publicações específicas dos temas que abordo.

Existem publicações e editorias especializadas, elaboradas por jornalistas com bastante experiência na área, mas há ainda muito espaço para se crescer nesse segmento.

$\mathrm{Na}$ maioria das revistas sérias, o que observo são matérias ao menos conceitualmente embasadas.

Gosto da cobertura de ciência dos jornais e de revistas semanais, não gosto da cobertura de algumas revistas especializadas em ciência.

Encontro boas matérias esporádicas nos grandes jornais impressos, mas há falta de conhecimento na TV e na internet.

Alguns são mais pessimistas em relação à cobertura, destacando a superficialidade, a incapacidade dos profissionais em identificar pautas interessantes, a ênfase à produção internacional e a falta de apuração. Há menções que a falta de qualidade é ainda mais evidente na internet.

Poucos são os veículos que conseguem transformar uma notícia científica em algo interessante para o público. Na internet, o problema é maior ainda, pois a necessidade de colocar uma nota no ar é tão grande, que a boa apuração, entrevistas e outros elementos que transforma o jornalismo (de forma geral) em jornalismo, são deixados de lado.

Acredito que o jornalismo científico veio se popularizando com o passar dos anos e erroneamente também tem se tornado mais superficial. Tanto na escolha de temas (fugindo de assuntos mais técnicos e científicos), quando no aprofundamento dos temas. Poucas são as matérias nos grandes veículos que respeitam a inteligência e interesse do público e fornecem informações científicas tanto para o leigo quanto para aquele que espera um pouco além do básico.

Comun. \& Inf., v. 15, n.1, p. 197-216, jan./jun. 2012 
A cobertura nos jornais impressos e revistas semanais é razoável. $\mathrm{Na}$ internet, infelizmente, a qualidade ainda é ruim.

Falta aprofundamento. Muitas vezes, as matérias são superficiais e simples, para que possam ser entendidas pelo público dos veículos. Não é um problema de apuração, mas sim de tratamento e apresentação das informações.

As revistas se dedicam principalmente a temas que despertem curiosidade. Parece que o espaço principal para aprender algo são os documentários do Discovery Channel e similares. Os jornais têm que dar conta principalmente da pauta do dia a dia, há pouco espaço para matérias mais amplas. Mas quando elas acontecem, o resultado costuma ser bem interessante.

Cobertura é muito fraca, pois pouco espaço é dado para a ciência e tecnologia. Além disso, a maior parte das matérias na área destaca realizações da ciência e da tecnologia de outros países, desprezando o excelente trabalho realizado nas universidades e institutos de pesquisa brasileiros.

Não vejo no país algum veículo que realmente leve informação científica relevante para um público abrangente.

Apesar de não me considerar jornalista especializado em ciência, acredito na abordagem que desperte o interesse no leitor leigo, que aproxime ciência do homem comum. Há muita dificuldade em cumprir esse papel na imprensa nacional.

Os jornalistas também mencionam que a cobertura tende a explorar o curioso da notícia, recebendo um tratamento apelativo ou divertido:

A cobertura tende a ser repetitiva, com os mesmos assuntos dominando a pauta. O tratamento que recebem busca ser divertido ou apelativo, sem dar uma noção de como a ciência é feita. O resultado acaba sendo uma listagem de curiosidades, sem dar conta do deslumbramento que a descoberta realmente traz. E sem aumentar de forma concreta a cultura científica da população.

Em muitos casos, [a cobertura é] marcada pelo sensacionalismo e descontextualização da cobertura (não há vínculo entre as pesquisas e as descobertas e outras instâncias, como a economia, o impacto no mercado de trabalho etc etc). Em alguns casos, os jornalistas são reféns das fontes, muitas vezes comprometidas com interesses políticos e comerciais.

Comun. \& Inf., v. 15, n.1, p. 197-216, jan./jun. 2012 
Foca muito em curiosidades e soluções salvadoras. As manchetes em geral são sensacionalistas. Não cobertura de políticas de ciência e tecnologia.

Os pesquisados destacam a importância do profissional bem preparado para a cobertura especializada em ciência, com conhecimento sobre o processo científico, e mencionam que a falta de qualidade vem da falta de investimento dos veículos em formar equipes mais competentes:

Cobertura não regular, episódica ou circunstancial da área de ciência, tecnologia e inovação e que depende do perfil do jornalista porque a maioria dos veículos não dispõe de editoria ou equipe de profissionais para este tipo de cobertura. Há bons

exemplos a destacar e bons jornalistas na área, mas a cobertura, na média, apresenta os problemas apontados anteriormente.

Falta conhecimento do processo científico pelos jornalistas, pois tentam simplificar o processo científico como um sendo apenas de investigação e resultados e não de aceitação empírica e reprodutibilidade do experimento e da comprovação científica com avaliação pelos pares.

Se pensarmos apenas no público leigo, acho que falta mais didatismo para explicar descobertas da ciência, por exemplo.

Talvez a redação pudesse ser mais bem trabalhada, mas para isso seria necessário que os redatores também buscassem mais conhecimento específico sobre jornalismo científico. Atualmente, os editores é que acabam tendo de dar uma linguagem diferenciada, quando assim tem tempo para fazê-lo.

Ainda é grande a dependência dos papéis, ainda é grande o apego à visão dos cientistas, ainda há muito otimismo sobre o andamento (ou sucesso) das pesquisas apresentadas, ainda se explora pouco os outros elementos (humanos e não humanos) que integram a produção científica, ainda falta uma linguagem jornalística adequada para tratar de ciência.

O grande diferencial do jornalista científico “(...) é ir além do noticiar e contextualizar, mostrar como a ciência impacta a vida das pessoas e os interesses por trás dela, também é raro atualmente."

$\mathrm{Na}$ última pergunta também se utilizou a mesma estratégia da questão anterior: "Você considera que o perfil dos jornalistas que cobrem ciência mudou nos últimos anos?". "Por favor,

Comun. \& Inf., v. 15, n.1, p. 197-216, jan./jun. 2012 
justifique a sua resposta." Treze disseram que o perfil mudou, três disseram que não mudou, dois não responderam e dois disseram que não sabem.

A justificativa mais relevante para a mudança do perfil é a formação especializada. Os jornalistas alegaram que isso ajuda o profissional e reflete na cobertura.

Tenho visto um número maior de jornalistas mais especializados em jornalismo científico. Embora eu não considere que seja necessária uma formação em jornalismo ou em ciência (...) uma especialização de maneira a ter maior compreensão de temas científicos é essencial. Acho que a tendência é melhorar a cobertura cada vez mais.

Alguns jornalistas que cobrem ciência, tecnologia e inovação regularmente têm feito cursos de especialização, mestrado ou doutorado na área de ciências em universidades reconhecidamente de prestígio, inclusive no exterior e, apoiados na maior oferta de informações, têm qualificado a sua cobertura. Mas isso vale para os grandes centros e os veículos com maior estrutura. Há bons jornalistas especializados em ciência em algumas empresas.

"Vc" "eh" obrigado a mudar, pois as noticias proliferam e os temas exigem cada vez mais a pesquisa sobre o que se vai relatar para que o leitor leigo entenda o conteúdo do texto e se sinta bem ao ler.

Noto que os profissionais estão buscando cursos de especialização para atuar em áreas específicas, o que é essencial na hora de detalhar pautas e redigir textos.

Acho que antes os jornalistas eram mais especializados no tema. Não creio que a especialização seja fundamental, mas ajuda muito, sobretudo na hora de criar metáforas e paralelos que tornem o texto mais compreensível para o público leigo.

Me parece haver um interesse maior de jovens jornalistas na área, e vários dos jornalistas já empregados na grande imprensa buscaram fazer cursos profissionalizantes como o MIT, que eu fiz em 2007.

Estão mais especializados no assunto.

Os jornalistas têm buscado se especializar

Comun. \& Inf., v. 15, n.1, p. 197-216, jan./jun. 2012 
Alguns mencionam que a mudança no perfil ocorre não em razão de uma especialização profissional, mas porque a ciência está mais acessível, além de o público também se interessar mais sobre o tema.

Ciência, em geral, está mais acessível e é mais consumida hoje do que há dez anos, por exemplo. Os jornalistas mais jovens acompanham esse movimento. Em outras palavras, vejo como tendência que o assunto ciência está menos restrito, menos privativo - e isso vale para os jornalistas que cobrem o assunto. Há menos "especialistas" e mais gente capaz de fazer uma leitura de assuntos científicos diversos.

Ainda de acordo com a resposta anterior, acho que o perfil mudou à medida que a ciência e tecnologia "foi" se tornando "descolada". Jovens passaram a se interessar mais pelo tema, e acredito que, com isso, o perfil dos jornalistas também mudou. Além da questão do diploma, já que médicos e cientistas escreviam bastante sobre estes temas, agora a tecnologia é um tema do dia a dia dos jovens, que não veem mais o tema com distanciamento ou algo vinculado à escola, por exemplo.

Há ainda quem considere que a cobertura está pior, por causa do excesso de trabalho dos jornalistas.
Antigamente, os jornalistas eram mais especialistas no assunto. Hoje, acabam tendo de trabalhar em diversos assuntos e acabam perdendo um pouco do caminho da melhoria contínua em seus conhecimentos e desenvolvimentos sobre assuntos específicos de matérias científicas.

Nas respostas à questão 12 , alguns mencionam que não houve mudança no perfil do jornalista que atua na cobertura em ciência, tendo em vista que não há rotatividade desses profissionais.

Praticamente as mesmas pessoas escrevem sobre ciência nos últimos anos nos mesmos jornais e revistas! A renovação é pequena

Os que disseram não saber responder a questão sobre mudanças no perfil do jornalista que cobre ciência alegam não identificar um perfil especializado. Apresentam suspeitas, mas não afirmam. 
Não saberia dizer. Nunca cheguei a reconhecer um perfil determinado. Já vi pessoas na área com as mais diferentes aptidões e interesses. nas revistas muitos pareciam ter chegado lá um pouco por acaso, sem nenhuma ambição ou interesse prévio pelo tema.

Parece-me que, na maior parte dos casos, o jornalismo dito científico continua a ser feito por profissionais que não necessariamente têm especialização na área.

\section{Considerações Finais}

$\mathrm{Na}$ amostra pesquisada, verificou-se que o perfil dos jornalistas que atuam em ciência em jornais, revistas e internet pode ser sintetizado em: profissionais graduados em jornalismo (quase a totalidade), com idade acima de 30 anos, na faixa entre 30 e 40. A maioria atua em cargos de chefia, como editores, ou seja, são profissionais com mais experiência em jornalismo (quase a metade dos consultados tem mais de 10 anos de profissão, os demais entre 2 e 10 anos). Os respondentes atuam principalmente em revista e internet, porém dois atuam em editorias de jornais de grande circulação.

Foi possível verificar também que a amostra apresenta um equilíbrio entre os que têm formação especializada em jornalismo científico e os que não possuem. $\mathrm{O}$ fato de assumirem postos-chave nas redações, e se manterem neles, talvez possa ser consequência dessa especialização. Porém é importante destacar que nem todos que buscaram aprimoramento acadêmico na área consideram isso fundamental para o bom desempenho na cobertura de ciência. Poucos têm mestrado ou doutorado em jornalismo científico.

Embora os dados coletados na pesquisa de campo não possam ser generalizados, pois refletem apenas características e opiniões dos jornalistas que compõem a amostra não probabilística desta investigação, é possível, tendo em vista as questões conceituais levantadas nos tópicos iniciais, obter algumas pistas sobre a relação entre o perfil do jornalista que atua em ciência e a qualidade da cobertura realizada na área.

A maioria dos respondentes considerarem que o perfil do jornalista mudou, salientando a formação especializada na área de ciência como principal responsável, com a realização de cursos em diversos níveis (extensão, lato sensu e stricto sensu). É como disse Caldas (CARVALHO,

Comun. \& Inf., v. 15, n.1, p. 197-216, jan./jun. 2012 
2011), que ressalta a importância de uma formação especializada, um conhecimento sobre a ciência nos seus aspectos históricos, filosóficos, éticos, metodológicos e de linguagem.

Apesar de valorizarem a formação especializada, observa-se também que a maioria dos participantes da pesquisa avalia a cobertura jornalística em ciência como "regular", com críticas severas à falta de aprofundamento, ao tipo de abordagem (divertida, curiosa, sensacionalista), à falta de habilidade em transformar pautas em ciência em notícias atraentes, entre outras informações. Nesse aspecto há duas hipóteses: se a cobertura não reflete a mudança qualitativa desse profissional a dinâmica nas redações seria um entrave, considerando a visão de Bueno (2011) sobre o jornalismo científico; ou que mesmo a formação existente, por priorizar os resultados em vez do processo, por ser mais instrumental que reflexiva, não contempla as necessidades de uma cobertura aprofundada, contextualizada, didática, crítica e criativa, como aponta o estudo de Caldas et al (2011).

Os profissionais consultados têm clareza sobre a necessidade de que o jornalista tenha uma capacidade de leitura sobre a realidade científica e consiga passar isso ao leitor leigo, de maneira acessível, mas esse ideal ainda parece longe da realidade das redações.

A metodologia jornalística (TAVARES, 2011), que abrange a apuração exaustiva para a contextualização e o aprofundamento do fato, parece distante, pelo menos na visão dos participantes deste estudo. Há que se ressaltar que alguns consideram momentos de excelência no jornalismo científico, como em coberturas em editorias de jornais impressos e em revistas especializadas. Parece que o impresso se destaca como um espaço mais próximo do ideal de jornalismo científico, sendo as coberturas em internet, rádio e TV exemplificadas como menos qualificadas.

Finalizando, pelos dados apresentados e as referências teóricas neste artigo foi possível verificar que o jornalismo especializado não é diferente. Antes de qualquer coisa, ele possui uma prática e um processo comum ao praticado pelos demais especialistas e generalistas. O jornalismo especializado pode também ser segmentado, isso implica em diversidade de gêneros e linguagem, ou seja, não podemos afirmar, tal qual Tavares (2011), que apenas um gênero pode representá-lo. Entre os autores pesquisados, a especialização do jornalismo se dá pela temática, muito mais que qualquer outra característica. Que a prática do jornalismo especializado está ligada ao tipo de veículo, público ao qual se destina estratégia editorial, linguagem e formação dos profissionais que nele atuam. Mais que isso, está associado ao compromisso de levar informação e consciência crítica à população brasileira, de modo a criar uma "cultura científica", como diz Caldas (2011). 
Nos dados levantados pôde ser verificado que há sim uma tendência à especialização dos profissionais, além de uma visão bastante crítica quanto à cobertura. A maioria aponta a especialização como fator positivo na mudança do jornalista científico, porém, ainda com poucos reflexos na cobertura. A investigação sobre essa aparente contradição pode estar ligada aos processos de produção, às limitações de tempo, às questões comerciais e mercadológicas dos veículos jornalísticos. As pistas foram deixadas pelos jornalistas que colaboraram com este artigo.

\section{Referências}

AMENDOLA, Beatriz. Quem são os jornalistas? Disponível em: <http://www.eca.usp.br/jornalismoemclasse/?p=216>. Acesso em: 20 fev. 2012. BUENO, Wilson da Costa. Jornalismo científico. Disponível em: <http://www.jornalismocientifico.com.br/jornalismocientifico/conceitos/jornalismocientifico.php>. Acesso em: ago. 2011.

. O que está faltando ao jornalismo científico brasileiro? Disponível em:

$<$ http://www.jornalismocientifico.com.br/jornalismocientifico/artigos/jornalismo_cientifico/artigo2 5.php>. Acesso em agosto de 2011.

CALDAS, Graça et al. O desafio da formação em Jornalismo Científico. Disponível em: <http://dialnet.unirioja.es/servlet/articulo?codigo=2071134>. Acesso em: ago. 2011. CARVALHO, Cristiane Portela. Divulgação científica nas revistas Ciência Hoje, Scientific American Brasil e Superinteressante: estudo comparativo. Doutorado. São Bernardo do Campo: Universidade Metodista de São Paulo, ago. 2011.

CHAPARRO, Manuel Carlos. Sotaques d'aquém e d'além-mar: percursos e gêneros do jornalismo português e brasileiro. Santarém: Jortejo, 1998.

DINES, Aberto. Os desafios da mídia institucional. Disponível em: <http://www.aberje.com.br/antigo/revista/n22/artigo4d.htm>. Acesso em: 4 mar. 2012.

GENRO, Adelmo. O segredo da pirâmide: para uma teoria marxista do jornalismo. Porto Alegre: Tchê, 1987.

GROTH, Otto. O poder cultural desconhecido: fundamentos da ciência dos jornais. Trad. Lilian Sponholz. Petrópolis: Vozes, 2011.

MORAES, Elizabeth Gonçalves. Cenografia especial para a divulgação científica: um estudo da revista Superinteressante. Disponível em: <http://elizabethgoncalves.pro.br/2009/11/19/cenografiae-divulgacao-cientifica-um-estudo-da-revista-superinteressante/>. Acesso em: out. 2011. NAVARRO, José Gabriel. O discurso sobre a crise de 2008 nos editoriais de Meio\&Mensagem. Monografia. Universidade Metodista de São Paulo, Faculdade de comunicação, Curso de Jornalismo, 2010.

ROVIDA, Mara Ferreira. A segmentação no jornalismo sob a ótica durkheimiana da divisão do trabalho social. Tese. Faculdade Cásper Líbero, São Paulo: 2010.

TAVARES, Frederico de Mello Brandão. O jornalismo especializado e a especialização periodística. Estudos em comunicação, Rio Grande do Sul, n. 5, p.115-133, maio 2009. 
O jornalismo especializado e a mediação de um ethos contemporâneo na sociedade. Em Questão, Porto Alegre, v. 13, n. 1, p. 41-56, jan/jun 2007.

Comun. \& Inf., v. 15, n.1, p. 197-216, jan./jun. 2012 